SUBJECT AREAS:

NANOBIOTECHNOLOGY

HEALTH CARE

BIOTECHNOLOGY

Received

4 November 2013

Accepted

26 January 2015

Published

24 March 2015

Correspondence and requests for materials should be addressed to U.D. (utkan@stanford. edu) or A.D. (aykutlu@

fen.bilkent.edu.tr)

* These authors contributed equally to this work.

\section{Portable Microfluidic Integrated Plasmonic Platform for Pathogen} Detection

Onur Tokel ${ }^{*}$, Umit Hakan Yildiz ${ }^{2 *}$, Fatih Inci ${ }^{2}$, Naside Gozde Durmus ${ }^{3,4}$, Okan Oner Ekiz ${ }^{5}$, Burak Turker ${ }^{5}$, Can Cetin', Shruthi Rao', Kaushik Sridhar', Nalini Natarajan', Hadi Shafiee', Aykutlu Dana ${ }^{5}$ \& Utkan Demirci ${ }^{1,2}$

'Demirci Bio-Acoustic-MEMS in Medicine (BAMM) Laboratory, Center for Biomedical Engineering, Department of Medicine, Brigham and Women's Hospital, Harvard Medical School, Boston, MA, USA, ${ }^{2}$ Demirci Bio-Acoustic-MEMS in Medicine (BAMM) Laboratory, Stanford University School of Medicine, Canary Center at Stanford for Cancer Early Detection, Palo Alto, CA, USA, ${ }^{3}$ Department of Biochemistry, Stanford School of Medicine, Stanford, CA, USA, ${ }^{4}$ Stanford Genome Technology Center, Stanford University, Palo Alto, CA, USA, ${ }^{5}$ UNAM Institute of Materials Science and Nanotechnology, Bilkent University, 06800 Ankara, Turkey.

Timely detection of infectious agents is critical in early diagnosis and treatment of infectious diseases. Conventional pathogen detection methods, such as enzyme linked immunosorbent assay (ELISA), culturing or polymerase chain reaction (PCR) require long assay times, and complex and expensive instruments, which are not adaptable to point-of-care (POC) needs at resource-constrained as well as primary care settings. Therefore, there is an unmet need to develop simple, rapid, and accurate methods for detection of pathogens at the POC. Here, we present a portable, multiplex, inexpensive microfluidic-integrated surface plasmon resonance (SPR) platform that detects and quantifies bacteria, i.e., Escherichia coli (E. coli) and Staphylococcus aureus ( $S$. aureus) rapidly. The platform presented reliable capture and detection of $E$. coli at concentrations ranging from $\sim 10^{5}$ to $3.2 \times 10^{7} \mathrm{CFUs} / \mathrm{mL}$ in phosphate buffered saline (PBS) and peritoneal dialysis (PD) fluid. The multiplexing and specificity capability of the platform was also tested with $S$. aureus samples. The presented platform technology could potentially be applicable to capture and detect other pathogens at the POC and primary care settings.

\footnotetext{
-
} merging micro- and nano-scale bioengineering and biomedical technologies have provided broad applications (e.g., medical diagnostics and biosensors) in health sciences. Developing such platforms that are affordable and rapid for infectious diseases is one of the top priorities for improving human health at the point-of-care (POC) settings ${ }^{1-4}$. Currently, the standard testing for pathogen detection and quantification are based on cell culture methods, which take 48 to 72 hours $^{5-7}$. Other detection methods such as polymerase chain reaction (PCR) and enzyme linked immunosorbent assay (ELISA), have been widely used to detect and quantify pathogens with high sensitivity and specificity ${ }^{8}$. However, they require expensive equipment and well-trained operators. Additionally, these assays are technically complex and need labor-intensive processing steps. Thus, rapid and inexpensive diagnostic methods are needed that will eliminate peripheral instrumentation and allow to deploy them to the POC. With the ongoing miniaturization in electronics, emerging technologies could allow portable instruments and minimize the need for bulky laboratory infrastructure at the POC and primary care settings ${ }^{9}$. Such self-contained and robust diagnostic devices could also lead to developing strategies for disease monitoring and management ${ }^{10}$.

Microfluidics, being at the convergence of micro/nanoscale engineering, materials science, and biology enables medical solutions for infectious disease diagnostics and monitoring ${ }^{11}$. Microfluidic technologies have been used to manipulate microliter sample volumes and minimize reagent costs in several applications including cryobiology, genetic and proteomic analysis controlling cancer microenvironment, and cell capture and cell release studies $^{11-17}$. In particular, analysis of bioagents (e.g., pathogens and infectious agents) is possible with microfluidic technologies. For instance, capture and detection of intact viruses on microchips have been demonstrated ${ }^{18}$. Microfluidic based diagnostic technologies have various characteristics, such as inexpensive fabrication, adaptability and rapid results ${ }^{19-21}$. Integrating microfluidic platforms with optical imaging systems combines the advantages of lab-chip platforms with the benefits of optical technologies ${ }^{22,23}$. In particular, photonics and 
plasmonics, e.g., surface plasmon resonance (SPR), localized surface plasmon resonance (LSPR) and nanostructured photonic crystals, being at the intersection of nanotechnology and optics, can be used for developing reliable, accurate, easy-to-use biosensor platforms ${ }^{24-28}$. Plasmonic lab-chip devices could be constructed as affordable platforms by utilizing single-use, disposable microchips for POC testing. In addition, disease specificity could be attained by using various surface functionalization techniques. In plasmonic sensor technologies, for instance SPR platforms, a biomolecular recognition element is immobilized on metal surfaces (e.g., gold, silver) for efficient, specific and selective capture of bioagents. The limit of detection of SPR-based detection systems are affected by factors including the target immobilization method (by affecting the affinity), sample volume and transport properties (by affecting the probability of capturing the target), the refractive index of the target, and practical device parameters ${ }^{25,29,30}$. Microfluidics helps to handle small sample volumes that affects overall sensor performance and capture kinetics ${ }^{31}$.

Here, we present such a microfluidic-based SPR technology. We validated this portable platform with Escherichia coli (E. coli) and Staphylococcus aureus (S. aureus) spiked samples as a model pathogen detection system. Disposable microfluidic chips with gold coated surfaces were functionalized with antibodies for efficient, selective and specific capture of E. coli and S. aureus. We quantified the captured E. coli with brightfield and fluorescence imaging, and analyzed the capture distribution spatially along the microchannels. Limit of detection of the platform was evaluated, and standard curves were generated for E. coli spiked in phosphate buffered saline (PBS) and peritoneal dialysis (PD) fluid. Multiplexing and selectivity capability was also assessed with $S$. aureus spiked in PBS samples.

Microfluidic chip with gold coating

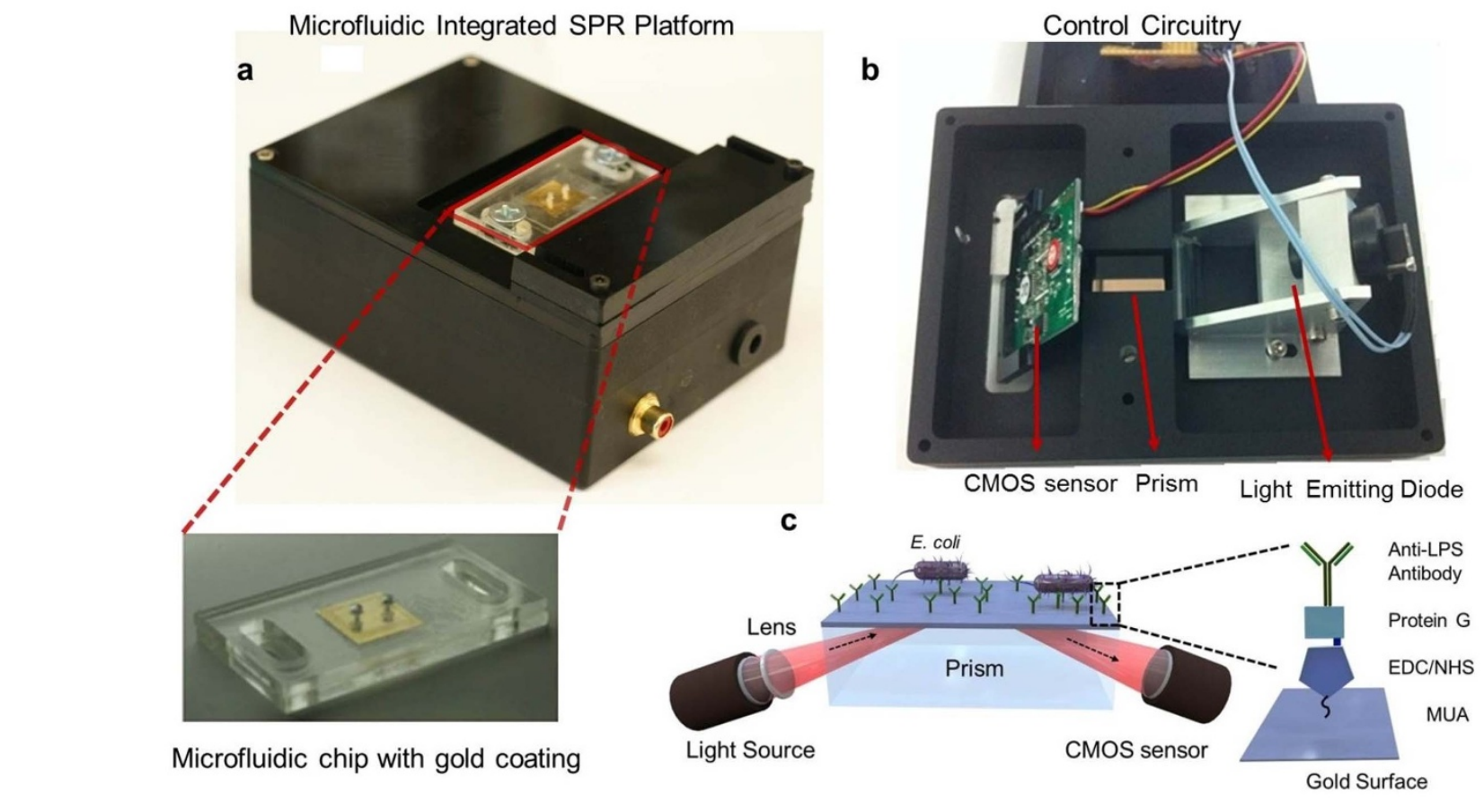

\section{Methods}

Design and fabrication of microfluidic chips. The microfluidic chip design comprises a single microchannel with an inlet and an outlet port. The microchip with dimensions $31 \mathrm{~mm} \times 57 \mathrm{~mm} \times 7 \mathrm{~mm}$ was constructed as a cartridge for the platform. Two PMMA (poly methyl methacrylate) (3.0 mm thick; McMaster Carr, Atlanta, GA) layers were assembled using a layer of double sided adhesive (DSA, $50 \mu \mathrm{m}$ thick; iTapestore, Scotch Plains, NJ). A second DSA layer (50 $\mu \mathrm{m}$ thick) and a gold coated substrate formed the microchannel. The microchannel $(12 \mathrm{~mm} \times 7 \mathrm{~mm}$ $\times 50 \mu \mathrm{m})$ was located in the center of the microchip. The PMMA-DSA-PMMADSA-gold chip was assembled as a single use, disposable microchip (Figure 1 and S1). To fabricate the chip, the PMMA and DSA were cut using a laser cutter (Versa Laser $^{\mathrm{TM}}$, Scottsdale, AZ). The two PMMA layers were assembled with a layer of DSA Two openings were cut on the PMMA layer $(0.7 \mathrm{~mm}$ diameter) that formed the inlet and outlet ports. The distance between these ports was $9 \mathrm{~mm}$. The port openings with diameters of $1.4 \mathrm{~mm}$ in DSA allowed fluid transfer without interruption. A second DSA layer formed a microchannel in the center of the microchip with a channel volume of $4 \mu \mathrm{L}$. The design of the microchannel included sharp-edged ends. Finally, a gold chip of dimensions $1.4 \mathrm{~cm} \times 1.4 \mathrm{~cm}$ was mounted onto the microchip. The microchip design allows future extension of functionality, for instance by incorporating a filter to isolate cells, such as white or red blood cells as shown before ${ }^{32}$

Design and fabrication of gold coated glass surfaces. To realize disposable microfluidic chips, glass wafers (Borofloat, Double Side Polished, diameter = $100 \mathrm{~mm}, \mathrm{t}=0.5 \mathrm{~mm}$ ) were purchased from University Wafer, Boston, MA (Item 517), and were cleaned with acetone and isopropyl alcohol on the spinner cleaning instrument (Headway PWM-32 Spinner). Then, the wafers were loaded on the sample holders of an electron beam depositor (Denton E-beam Evaporator) for metal deposition. The system was operated at $10^{-7}$ Torr, and the wafers were deposited with $5 \mathrm{~nm}$ of titanium, followed by a $50 \mathrm{~nm}$ deposition of gold on a single side.

Subsequently, the metal coated wafers were spin coated with a $\sim 0.5 \mu$ m layer of S1805 photoresist (Shipley 1800-series photoresist) to protect the surface of the gold layer from environmental effects. The spinner was run at $4000 \mathrm{rpm}$ for 40 seconds, and later, baked at $115^{\circ} \mathrm{C}$ on a hot-plate for 2 minutes. The wafers were cut in $1.4 \mathrm{~cm}$ $\times 1.4 \mathrm{~cm}$ square chips using a mechanical dicer (DISCO DAD321 Dicing Saw) and stored after cleaning with distilled water. Before microfluidic chip fabrication, the gold chips were cleaned with solvents to remove any organic residues from the fabrication process. In a solvent bench, chips were placed in an acetone bath and

Figure 1 Portable plasmonic platform for pathogen detection and quantification. (a) The surface activated disposable microfluidic chips were mounted on the top side of the device. The microchip with the inlet and outlet ports, and the $50 \mathrm{~nm}$ thick gold coated glass substrate along with the disposable microchip is shown below. (b) The electronic setup of the device is represented from bottom. A light emitting diode illuminates a cylindrical lens, which collimates the light onto a rectangular prism. The reflected light is captured by a CMOS sensor, and the image is transferred to a portable computer using the control circuitry. The microfluidic chip is placed on the rectangular prism, with an refractive index matching oil in between. (c) Schematics of the microfluidic integrated SPR platform. The gold surfaces were modified with several activators (i.e., 11-Mercaptoundeconoic Acid (MUA), N - (3 - Dimethylaminopropyl) - $\mathrm{N}^{\prime}$-ethylcarbodiimide Hydrochloride (EDC), N-Hydroxysuccinimide (NHS) and with anti-

Lipopolysaccharide (LPS) antibody to capture the E. coli. The bacteria are captured by the antibodies in the microchannel, and the capture event induces a change in the local refractive index. This change provides a signature on the reflected light, which is captured by the sensor and transferred to a computer for analysis. 
sonicated for 5 minutes. Then, they were transferred to a methanol bath and sonicated for 5 minutes again. Finally, chips were transferred to an isopropanol bath and gently shaken for final cleaning. The gold chips were then dried with nitrogen gas to be used in the fabrication of the microfluidic chips.

E. coli culture and quantification. To analyze and visualize the bacteria distribution on the microchip, a green fluorescent protein expressing plasmid, pRSET/EmGFP (Invitrogen, V353-20), was transferred into the competent $E$. coli strain BL21 Star ${ }^{\mathrm{TM}}$ (Invitrogen, C6000-03). According to the manufacturer's instructions, the pRSET/ EmGFP plasmid, which confers ampicillin resistance, was incubated at $42^{\circ} \mathrm{C}$ for 30 seconds with the competent cells. Cells were allowed to cool down on ice for 2 minutes. $250 \mu \mathrm{L}$ of Super Optimal broth with catabolite repression medium (Sigma-Aldrich, S1797) was added to be incubated for an hour at $37^{\circ} \mathrm{C}$, while shaking at $250 \mathrm{rpm}$. Subsequently, the genetically modified bacteria were spread onto Luria Bertani (LB) agar plates, which contained $100 \mu \mathrm{g} / \mathrm{mL}$ of ampicillin. The plates were incubated at $37^{\circ} \mathrm{C}$ for 16 hours, and cells were allowed to grow. When colonies appeared, an individually isolated colony was inoculated in a $30 \mathrm{~mL}$ of $\mathrm{LB}$ broth, containing $100 \mu \mathrm{g} / \mathrm{mL}$ ampicillin. Then, E. coli culture was incubated for 16 hours in a $250 \mathrm{rpm}$ rotating incubator at $37^{\circ} \mathrm{C}$ and aliquoted for later use as a standard stock.

The E. coli stock concentration was quantified by diluting the stock solution ninefold in PBS and spreading the dilution onto LB-ampicillin plates to be incubated at $37^{\circ} \mathrm{C}$ overnight. Finally, individual E. coli colonies were counted, and the concentration of the stock solution was calculated as $10^{9} \mathrm{CFUs} / \mathrm{mL}$. By diluting the stock concentration into PBS, the concentrations in the experiments were obtained.

For peritoneal dialysis (PD) fluid experiments, E. coli was spiked in a commercial dialysate, received from Chronic Ambulatory Peritoneal Dialysis (CAPD) Unit from Faulkners Hospital (Baxter Inc., 5B9766). Sample concentrations ranging from $10^{5}$ to $3 \times 10^{7} \mathrm{CFUs} / \mathrm{mL}$ were prepared by serial dilution in PD fluid.

S. aureus culture and quantification. S. aureus (ATCC \#25923, American Type Culture Collection, Mannassas, VA) cells were hydrated and streaked for isolation on a Luria Bertani agar (LA) plate. Following growth, a single isolated colony was selected and inoculated in $3 \mathrm{~mL}$ of Luria bertani (LB) media. The bacteria culture was grown on an incubator shaker for 18 hours at $37^{\circ} \mathrm{C}, 250 \mathrm{rpm}$ until it reached the stationary phase. Quantification of $S$. aureus stock concentration was done by diluting the overnight cultures nine-fold in PBS. Diluted cultures were streaked onto LB Agar plates, incubated at $37^{\circ} \mathrm{C}$ overnight and individual S. aureus colonies were counted after overnight incubation. The concentration of stock cultures was calculated as $10^{9} \mathrm{CFUs} / \mathrm{mL}$. For validation experiments, the overnight cultures were diluted at a ratio of $1: 10$ in LB media.

Portable biosensor operating principle and fabrication. The SPR platform was custom-made for microfluidic integration (Figure 1a,b). The design of the system was based on Kretschmann configuration, which uses prism coupling to satisfy momentum conservation for plasmon excitation by an external light source ${ }^{33}$ (Figure 1c). A collimated point source light emitting diode (LED) output ( $\lambda=$ $705 \mathrm{~nm})$ was focused with a cylindrical lens $(\mathrm{f}=15 \mathrm{~mm})$ and passed through a glass prism (N-BK7, $\mathrm{n}=1.51)$ to illuminate the surface of the microchip. The rectangular prism was positioned on a stage, which was practical for inserting microfluidic chips and the prism. Reflected light was captured by a CMOS sensor $(500 \times 582)$, which was placed such that the normal of the sensor surface was parallel to the monitored light direction. The light source, CMOS sensor, and the associated optical and electrical components were packaged in a portable box with dimensions of $13.5 \mathrm{~cm} \times$ $10 \mathrm{~cm} \times 5.2 \mathrm{~cm}$ (length $\times$ width $\times$ height) (Figure 1a, b). The total weight of the packaged system was $0.85 \mathrm{~kg}$ ( $1.87 \mathrm{lbs})$. The disposable microfluidic chips were then placed on the prism with a thin layer of index matching liquid $(n=1.5000 \pm 0.0002$, Series A, Cargille Labs, NJ) and fixed in place (Figure 1a). The index matching liquid was used for providing lossless optical transmission between the prism and the glass substrate on the microchip. A custom-designed software was used to monitor the resonance angle changes. The software captured the image frames from the sensor, calculated the resonance angle in real time, and then, plotted the resonance curve and the sensogram (resonance angle as a function of time) as a readout for kinetic measurements.

Calibration. To calibrate the sensor, fluids (i.e., distilled water PBS and ethanol (200 proof)) with known refractive indices were used as reference samples, and their plasmon resonance curves were measured in microfluidic channels. Then, the instrument parameters were matched to these experimental curves to extract device fitting parameters. In the Kretschmann configuration, the surface plasmon mode's wave vector, $\mathrm{k}_{\mathrm{sp}}$, is described by $k_{s p}=\omega / c \sqrt{\varepsilon_{1} \varepsilon_{2} /\left(\varepsilon_{1}+\varepsilon_{2}\right)}$, where $\omega$ is the angular frequency of the incoming light, $c$ is the speed of light, $\varepsilon_{1}$ and $\varepsilon_{2}$ are the dielectric permittivity of the gold and biosensor medium ${ }^{34}$. The resonance condition occurs when the surface plasmon mode wave vector is equal to the incident light's wave vector in the plane of the interface, i.e., $\mathrm{k}_{\mathrm{sp}}=\omega / \mathrm{c}(n \operatorname{Sin} \theta)$ where $n$ is the refractive index of the prism and $\theta$ is the incidence angle of the light ${ }^{35}$. The calibration procedure allowed an active operating range of 67 to 73 degrees for the resonance angle and the smallest angle shift the device showed sensitivity was $0.002^{\circ}$. All calibration measurements and validation experiments were performed at room temperature.

Functionalization of microchannels for label-free $E$. coli and S. aureus capture and detection. The surface modification for E. coli and S. aureus detection was performed on the $50 \mathrm{~nm}$ gold coated glass wafers. The gold surfaces were first submerged in acetone bath at $56^{\circ} \mathrm{C}$ to clean any organic residues from the nanofabrication and chip dicing. The gold chips were incubated with $10 \mathrm{mM}$ of 11-Mercaptoundecanoicacid (MUA) (450561 Aldrich - Sigma Aldrich) dissolved in ethanol overnight, and thus, self-assembled monolayer with carboxyl groups was generated onto the surface. After MUA modification, microfluidic channels were constructed. Then, a $100 \mu \mathrm{L}$ of, $1: 1$ mixture of $100 \mathrm{mM} \mathrm{N}$ - (3 - Dimethylaminopropyl) - $\mathrm{N}^{\prime}$-ethylcarbodiimide Hydrochloride (EDC, 03450 Fluka - Sigma Aldrich) in 10 mL MES (M3671 Sigma Sigma Aldrich) buffer $\left(9,76 \mu \mathrm{g} / \mathrm{mL}\right.$ in $\left.\mathrm{dH}_{2} \mathrm{O}\right)$ and $50 \mathrm{mM}$ of $\mathrm{N}$-Hydroxysuccinimide (NHS, 130672 Aldrich - Sigma Aldrich) in $10 \mathrm{~mL}$ of MES buffer, was loaded with pipettes to microchips through the inlet port and incubated for 30 minutes. EDC reacts with carboxyl groups for the formation of amine reactive intermediate that is stabilized by the addition of NHS. The final chemical product is a succinimide group that reacts with amine groups of organic compounds (e.g., proteins). The surfaces were then washed with $100 \mu \mathrm{L}$ of distilled water and $300 \mu \mathrm{L}$ of PBS. This step was followed by introducing $100 \mu \mathrm{L}$ of Protein G $(0.1 \mathrm{mg} / \mathrm{mL})(21193$ - Thermo Scientific) dissolved in PBS for the immobilization of antibodies with their favorable orientations, and Protein $\mathrm{G}$ was incubated at $4{ }^{\circ} \mathrm{C}$ for an hour. The surfaces were then washed with $300 \mu \mathrm{L}$ of PBS. $100 \mu \mathrm{L}$ of anti-lipopolysaccharide (LPS) antibody (ab35654 - Abcam) $(5 \mu \mathrm{g} / \mathrm{mL})$ solution in PBS was incubated for 30 minutes, and thus, antibodies were immobilized on the Protein G coated layer to capture GFPexpressing E. coli. For S. aureus experiments, $100 \mu \mathrm{L}$ of anti-lipotheichoic acid (antiLTA) antibody (MA1-7401 - Thermo Scientific) $(5 \mu \mathrm{g} / \mathrm{mL})$ solution in PBS was incubated on Protein G-coated surfaces for 30 minutes. After another wash with $300 \mu \mathrm{L}$ of $\mathrm{PBS}$, various concentrations of $E$. coli ranging from $3.2 \times 10^{5}$ to $3.2 \times$ $10^{7} \mathrm{CFUs} / \mathrm{mL}$ in PBS were passed through the chip at $5 \mu \mathrm{L} / \mathrm{min}$ rate for detection. In PD fluid experiments, $10^{5}$ to $3.2 \times 10^{7} \mathrm{CFUs} / \mathrm{mL}$ of $E$. coli spiked in PD fluid were passed through the chip at $5 \mu \mathrm{L} / \mathrm{min}$ rate for detection. In S. aureus experiments, $5 \times$ $10^{6} \mathrm{CFUs} / \mathrm{mL}$ were tested for multiplexing and selectivity of the platform.

Statistical Analysis. To evaluate each SPR angle shift, we facilitated one-way analysis of variance (ANOVA) with Tukey's posthoc test followed with Bonferroni's Multiple Comparison Test for equal variances for multiple comparisons with statistical significance threshold set at $0.05(\mathrm{p}<0.05)$. Error bars in the plots represented standard error of the mean (SEM). All statistical analyses was performed using GraphPad Prism 5 software (GraphPad Software, Inc., La Jolla, CA).

\section{Results and Discussion}

E. coli capture and quantification in the microchannels. To capture E. coli on microfluidic chips, we utilized a Protein G-based surface chemistry that allows to immobilize antibodies in a favorable orientation $^{18}$. It was previously shown that anti-LPS presented highest capture efficiency among a set of antibodies (antiflagellin, anti-LPS and CD14) for on-chip E. coli capture when Protein G based surface chemistry was performed ${ }^{6}$. We adapted the surface chemistry for gold-coated substrates, to target E. coli capture on a microfluidic chip. The captured bacteria counts between the inlet and outlet ports were evaluated, for chip characterization as well as for the limit of detection measurements. To quantify the number of bacteria captured on gold surfaces, a $75 \mu \mathrm{L}$ of $10^{6} \mathrm{CFUs} / \mathrm{mL}$ E. coli was passed through surface functionalized microchips (Figure $2 \mathrm{a}$ ) at a $5 \mu \mathrm{L} /$ minute flow rate using a syringe pump. The GFP-expressing $E$. coli was fluorescence imaged under $10 \times$ magnification (Figure $2 b)$. To evaluate the capture specificity, brigthfield images and fluorescence images at $100 \times$ magnification of the same spot were compared (Figure 2c, d).

We first addressed two considerations, i.e., autofluorescence and clustering, which could potentially result in erroneous estimates of bacterial counts. Autofluorescence may interfere with the samples under study and could potentially result in erroneous estimates of bacterial counts. To confirm that the fluorescence spots in the images were coming from the bacteria (not from autofluorescence of other particles), we gathered bright field images of 16 locations $(99 \mu \mathrm{m} \times$ $66 \mu \mathrm{m})$ on a chip at $100 \times$ magnification and compared the morphology of $E$. coli observed in these images with green spots observed in the corresponding fluorescence images under $100 \times$ magnification. These images showed no autofluorescence effects (Figure 2c, d). Additionally, clustering of bacteria could also potentially result in under-quantifying the bacteria on the sample surface. Therefore, we required that each observed point with fluorescence under the $10 \times$ magnification images should be associated with a single bacteria and not resulting from the clustering of $E$. coli. To confirm these observations, we took a fluorescence image under $10 \times$ magnification and 25 
a

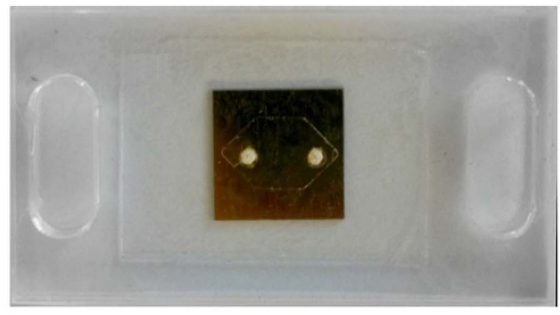

GFP cloned $E$. coli captured on gold b surface and imaged at 10X magnification

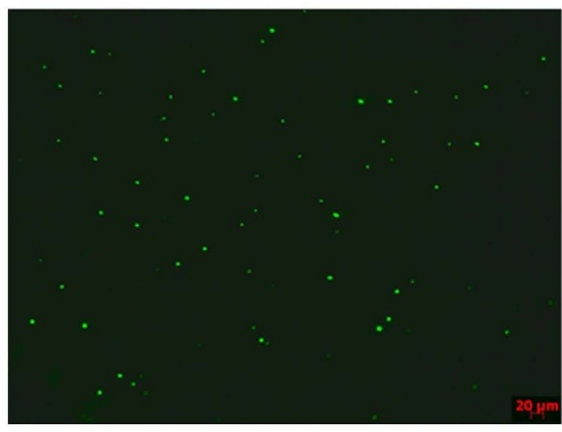

c GFP cloned E. coli at $100 \mathrm{X}-$ Fluorescence Image

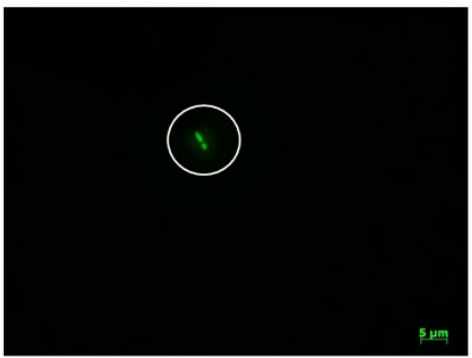

GFP cloned E. coli at 100X -

d Bright Field Image

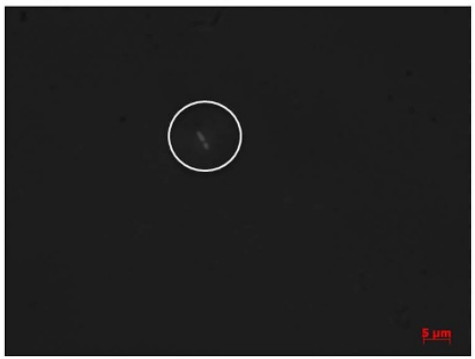

Figure $2 \mid$ Microfluidic chip and fluorescent images of $E$. coli taken under $10 \times$ and $100 \times$ magnifications in microchannels. (a) Microfluidic chip and the geometry of the channel formed by the $50 \mu \mathrm{m}$ thick double sided adhesive tape. (b) Captured GFP-expressing E. coli on the gold surface was fluorescently imaged at $10 \times$ magnification in the centre of the microchip. $75 \mu \mathrm{L}$ of $10^{6} \mathrm{CFUs} / \mathrm{mL}$ E. coli in PBS was run through the chip. The $10 \times$ fluorescence image was taken in the centre of the microchannel and was used to count the green fluorescing spots to give a count of 78. (c) Captured GFPexpressing E. coli was fluorescently imaged at $100 \times$ magnification. Bacteria are indicated with white circles. (d) Bright-field image at $100 \times$ magnification shows the morphology of bacteria, indicated with white circles, for the same image shown in (c).

fluorescence images with $100 \times$ magnification uniformly sampling the $10 \times$ image area. Using the twenty-five $100 \times$ images, we estimated a total of $82 \mathrm{E}$. coli on the imaged surface under $10 \times$ magnification. In comparison, 78 fluorescing points were counted in the $10 \times$ image. We concluded that clustering did not also play a significant role in the $10 \times$ image $E$. coli counts. Therefore, in the consecutive capture distribution analysis and limit of detection experiments, fluorescent images with $10 \times$ magnification are utilized for bacterial counts.

Capture Distribution Experiments. To evaluate the capture distribution of bacteria, six microchips were tested with $100 \mu \mathrm{L}$ of $10^{6} \mathrm{CFUs} / \mathrm{mL}$ E. coli spiked in PBS. The cell capture distribution along the microchannels were evaluated by identifying one longitudinal region passing through the inlet and outlet ports and three additional regions that are perpendicular to the flow direction in the microchannel. The captured E. coli were then manually quantified using fluorescence images taken under $10 \times$ magnification. The longitudinal region passing through the ports and center of the microchannel was evaluated with 10 images $(0.987 \mathrm{~mm} \times 0.658 \mathrm{~mm})$ under $10 \times$ magnification (Figure $3 \mathrm{a})$. The evaluated region covered the distance between the inlet and outlet ports. The maximum capture of E. coli was observed at 2$3 \mathrm{~mm}$ away from the inlet port and was consistent with previous microfluidic experiments on glass substrates ${ }^{36}$. The three regions perpendicular to the flow direction were also evaluated with fluorescence images under $10 \times$ magnification. One region perpendicular to the flow and passing through $1 \mathrm{~mm}$ to the right of the inlet, a second one passing through $1 \mathrm{~mm}$ to the left of the outlet and a third one passing through the center of the chip were evaluated with 7 images $(0.987 \mathrm{~mm} \times 0.658 \mathrm{~mm})$ each (Figure $3 \mathrm{~b}, \mathrm{c}$, and $\mathrm{d}$ ). The capture distribution showed a slight peak around the center of these regions but in general a uniform distribution was observed in the direction perpendicular to the flow.
SPR angle and kinetic measurements. The field of view of the sensor corresponded to an area of $1 \mathrm{~cm} \times 0.5 \mathrm{~cm}$ on the gold chip surface (Figure S2). The resonance angle was defined as the angle at which there was maximum light coupling to the plasmon modes ${ }^{37}$. The resonance condition was satisfied at angles corresponding to a band which was observed as a dark shadow on the camera (Figure S2a). The custom-developed software averaged the pixel intensities in a selected viewing area and converted the mean intensity as a function of distance to mean intensity as a function of the incidence angle. The minimum point of this band was calculated in real time and the SPR sensogram was generated, allowed the probing of surface events. A two inlet microchip was prepared for evaluating the rise time (i.e., time to increase from $10 \%$ to $90 \%$ of the resonance angle difference between the water and PBS signals) of the platform. Distilled water and PBS were alternately applied by syringe pumps at $5 \mu \mathrm{L} / \mathrm{min}$ flow rate, and the switching of liquids was evaluated. The rise time of the switching was observed as 8 seconds (Figure S2b, S2c).

For kinetic measurements and the evaluation of surface functionalization protocol, described in the Materials section (Functionalization of microchannels for label-free E. coli and S. aureus capture and detection section), the microchip surfaces were activated using syringe pumps at $5 \mu \mathrm{L} / \mathrm{min}$ flow rate, while they were mounted on the SPR platform. During the washout steps with PBS, we observed the signal stayed constant. Each modification step in the surface functionalization increased the resonance angle by changing the refractive index near the gold surface (Figure 4a). Protein G and anti-LPS binding were observed rapidly as well as other surface events at the interface (Figure 4a). Subsequently, this protocol was modified to be applied with pipettes, allowing for multiple microchip preparation in a parallel manner and used in the E. coli capture and detection experiments with the SPR platform. A representative resonance shift in the SPR curve upon capture and detection of bacteria is illustrated in Figure 4c. 

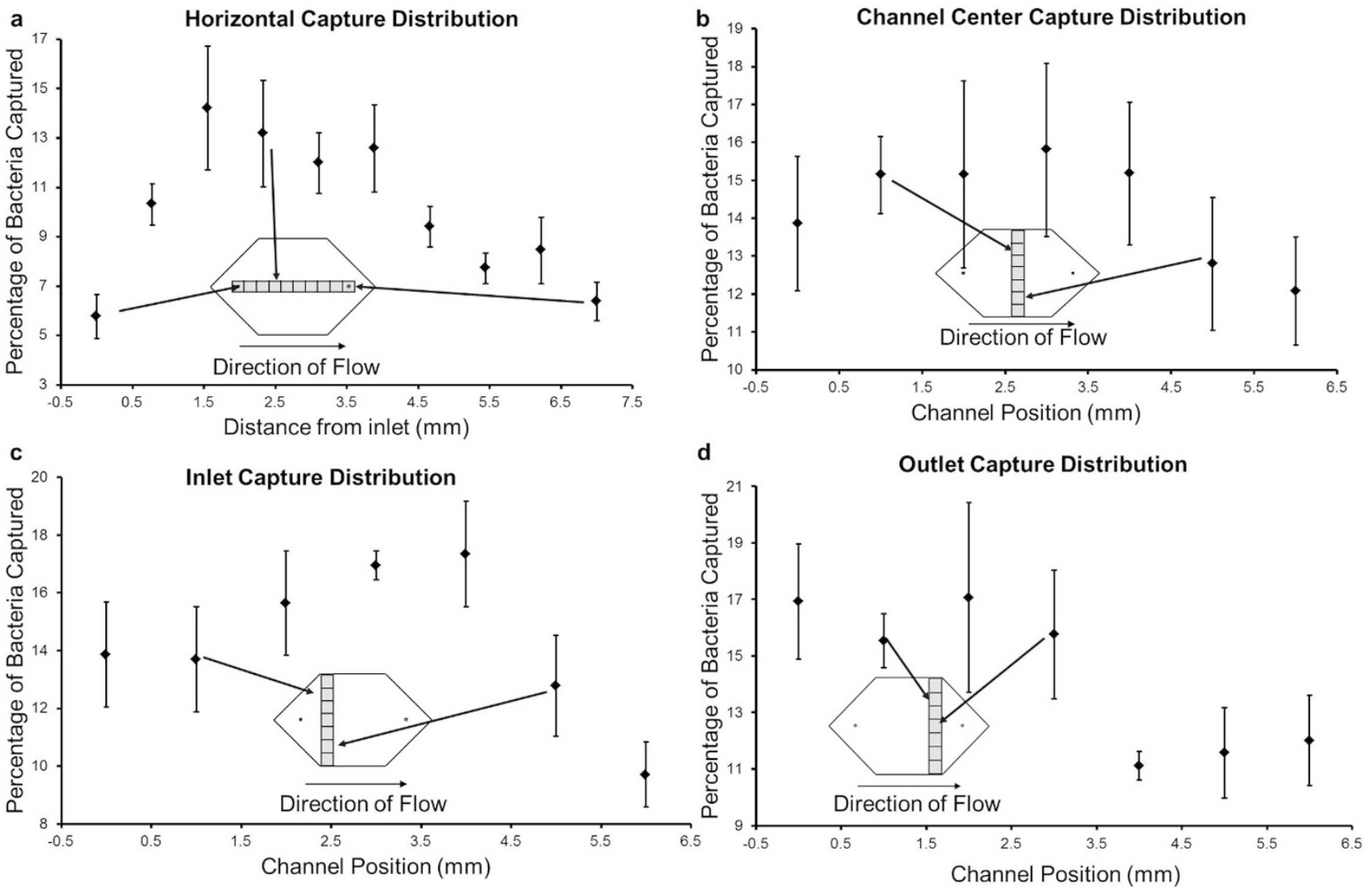

Figure 3 Capture distribution of $\boldsymbol{E}$. coli in microchannels. (a) The plot represents the overall percentage of captured $E$. coli in the microchannels through a horizontal stripe passing from the inlet port to the outlet port. The error bars represent the standard error of the mean $(\mathrm{n}=6)$. The capture distribution spatially peaks at $2 \mathrm{~mm}$ from the inlet port. During each run, $100 \mu \mathrm{L}$ of $10^{6} \mathrm{CFUs} / \mathrm{mL}$ E. coli was passed through the channel.

(b) Three stripes perpendicular to the channel direction were evaluated for capture distribution for the same chips evaluated in (a). The capture distribution for the stripe passing through the center of the channel is shown. (c) The distribution for the stripe passing close to the inlet port is shown. (d) The capture distribution for the stripe passing close to the outlet port is shown. The error bars indicate standard error of the mean normalized to the total E. coli count on each chip $(\mathrm{n}=6)$. Approximately a uniform capture distribution was observed in the direction perpendicular to the flow.

Limit of Detection and Standard Curves. In the literature, the limit of detection (LOD) of an SPR sensor is reported mainly as a function of the concentration of cells introduced to the system ${ }^{38}$. This metric does not take the sample volume into account. Therefore, we evaluated the LOD using two approaches. In the first approach, a fixed volume $(100 \mu \mathrm{L})$ was used, and the lowest detectable bacteria concentration was evaluated. Standard curves were also provided for bacteria quantification in PBS solution and in PD fluid. In comparison, the second approach evaluates the absolute number of bacteria captured within the active area of the sensor inducing a detectable resonance shift given a fixed concentration.

To evaluate the response range and potential applicability of the system to biological systems, we analyzed various concentrations of E. coli suspensions in PBS. A representative sensogram demonstrating E. coli detection is shown in Figure 4b. First, PBS was introduced into the surface functionalized channel, then $100 \mu \mathrm{L}$ of $10^{6} \mathrm{CFUs} /$ $\mathrm{mL}$ of $E$. coli was passed at $5 \mu \mathrm{L} /$ minute, and finally PBS was introduced again to wash unbound bacteria. We observed that the signal stayed constant during PBS runs, whereas a signal increase was observed in time when the E. coli was introduced. For the response curve analysis, E. coli concentrations of $3.2 \times 10^{5} \mathrm{CFUs} / \mathrm{mL}$, $10^{6} \mathrm{CFUs} / \mathrm{mL}, 2 \times 10^{6} \mathrm{CFUs} / \mathrm{mL}, 6.3 \times 10^{6} \mathrm{CFUs} / \mathrm{mL}, 2 \times$ $10^{7} \mathrm{CFUs} / \mathrm{mL}$, and $3.2 \times 10^{7} \mathrm{CFUs} / \mathrm{mL}$ spiked in PBS were evaluated at $5 \mu \mathrm{L} /$ minute flow rate (Figure 5). At each concentration, six microchips were run for 20 minutes to generate reliable signal levels.
The platform demonstrated a linear response $\left(\mathrm{R}^{2}=0.98\right)$ between the plasmon signal and the logarithm of the $E$. coli concentration within the $3.2 \times 10^{5}-3.2 \times 10^{7} \mathrm{CFUs} / \mathrm{mL}$ range. We observed plasmon shifts of $\sim 0.02^{\circ}$ and $\sim 0.38^{\circ}$ at concentrations $3.2 \times 10^{5}$ CFUs/ $\mathrm{mL}$ and $3.2 \times 10^{7} \mathrm{CFUs} / \mathrm{mL}$, respectively. The standard curve shown in Figure 5 can be used to calculate an unknown $E$. coli concentration spiked in PBS for quantitative analysis. The LOD for E. coli capture and detection with direct immunoassays in SPR-based systems is $\sim 10^{6} \mathrm{CFUs} / \mathrm{mL}^{39,40}$. Lower LODs have also been reported, but with bulky SPR systems that employ sandwich assays to improve the $\mathrm{LOD}^{41}$. For instance, a flow-cell based SPR sensor was reported to detect Salmonella typhimurium at $2.5 \times 10^{5}$ cells $/ \mathrm{mL}$ and Salmonella enteritidis at $2.5 \times 10^{8}$ cells $/ \mathrm{mL}$ with a sandwich assay ${ }^{42}$. It has been also noted that sample preparation may influence the signal levels. For instance, E. coli was detected using a sandwich assay with an LOD of $10^{4} \mathrm{CFUs} / \mathrm{mL}$ when the bacteria was lysed, $10^{5} \mathrm{CFUs} / \mathrm{mL}$ when the bacteria was heat-killed and with $10^{6} \mathrm{CFUs} / \mathrm{mL}$ with untreated E.coli ${ }^{43}$. The portable microfluidic-based SPR platform reported here provides a comparable with these different platforms. Although sandwich assays, sample labeling and modified sample preparation techniques can improve the reported LOD, these preprocesses increase the complexity, thus reducing the applicability in POC settings ${ }^{44}$. There are existing commercial SPR platforms reported $^{45-51}$ (Table S1). For instance, Biacore device is notably reported to detect $25 \mathrm{CFUs} / \mathrm{mL}$ of $E$. coli, using $25 \mu \mathrm{L}$ samples, cor- 

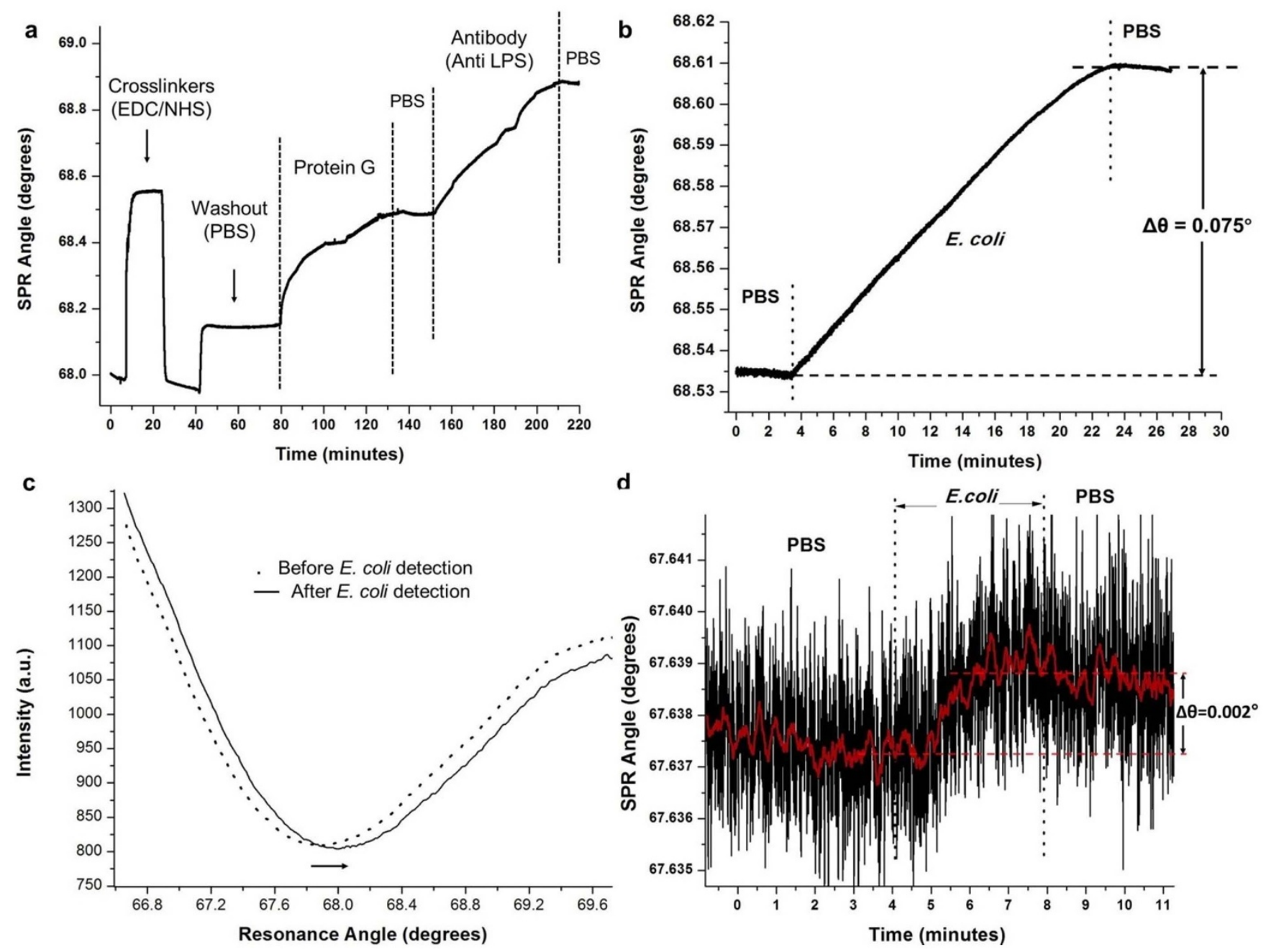

Figure $4 \mid$ Evaluation of the platform. (a) Real time monitoring of the surface chemistry steps with respect to surface plasmon resonance angle change. The modification of the gold surfaces with crosslinkers is followed by Protein G and antibody immobilization on the surface. The signal remains constant during the wash-out steps with PBS. (b) Representative detection curve of $E$. coli. First PBS was introduced into the channel, then $100 \mu \mathrm{L}$ of $10^{6} \mathrm{CFUs} / \mathrm{mL}$ E. coli was passed at $5 \mu \mathrm{L} /$ minute, and finally PBS was introduced again. (c) Representative plot of plasmon resonance shifts after the application of $E$. coli to the biosensing platform. The arrow indicates the plasmonic shift due to the detection of GFP-expressing $E$. coli, when $10^{6}$ $\mathrm{CFUs} / \mathrm{mL}$ E. coli was applied. The minimum point of the curves are the surface plasmon resonance angles. (d) Limit of detection evaluation from a $20 \mu \mathrm{L}$ sample is shown. Protein G and anti-Lipopolysaccharide (LPS)-based surface chemistry optimized for off-device activation was used to capture and detect $10^{6} \mathrm{CFUs} / \mathrm{mL}$ E. coli in PBS. $20 \mu \mathrm{L}$ of E. coli was passed through the channel and $\sim 0.002^{\circ}$ plasmon shift was observed. The $10 \times$ fluorescence images were used to count the green fluorescing spots, and we observed E. coli count of $32 \pm 1.6$ ( $\mathrm{n}=6$, error is given in standard error of the mean). The red curve shows a smoothed sensogram to show the limit of detection signal.

responding to an absolute value of $0.62 \mathrm{CFU} / \mathrm{mL}$ of E.coli (less than $1 \mathrm{CFU})$ in the total evaluated sample volume. This performance is reached at the expense of portability, since the Biacore laboratory equipment weighing $50 \mathrm{~kg}$ is not suitable for POC applications ${ }^{44,52}$. In comparison, this work reports a portable device $(0.85 \mathrm{~kg})$ suitable for POC applications, with a favorable LOD in comparison to the mean of the values given in Table S1. The platform reported here requires lower sample volume, as well as provides significant advantages using disposable chips and portable reader for POC applications.

As an example of a biologically relevant fluid, we evaluated the detection of $E$. coli samples spiked in PD fluid at the concentration range of $10^{5} \mathrm{CFUs} / \mathrm{mL}$ to $3.2 \times 10^{7} \mathrm{CFUs} / \mathrm{mL}$ (Figure 6). The platform performed well in comparison to the PBS experiments, with an $\mathrm{R}^{2}$ value of 0.98 for the linear fit. At the highest concentration of $3.2 \times$ $10^{7}$ CFUs/mL we observed a signal of $\sim 0.11$ degrees in comparison to the $\sim 0.38$ degrees of PBS experiments given in Figure 5 . We observed the slope of the linear fit was slightly smaller. PBS and PD fluid have different chemical and optical properties (e.g., refract- ive index, $\mathrm{pH}$ ), which may contribute to the resonance angle shifts observed in experiments at the same E. coli concentrations. During the PD fluid experiments the experimental parameters (i.e., surface functionalization, chip design) were kept the same as in the PBS experiments, however a different batch of gold coated chips were used, which may also have contributed to the difference in the observed signal levels.

In the second LOD approach, we evaluated the absolute number of cells that the system is sensitive to, which was defined as the absolute LOD. Multiple sample volumes between $20 \mu \mathrm{L}$ and $100 \mu \mathrm{L}$ were evaluated to characterize the experimental detection limitation of the system. The active area on the gold chip surface $(5.3 \times$ $10^{6} \mu \mathrm{m}^{2}$ ) inducing this signal was selected (Figure S2) and fluorescence images at $10 \times$ magnification were collected after separating the gold substrates from the microchips. For each chip, nine images were acquired under $10 \times$ magnification, and the GFP-expressing bacteria were counted inducing the signal. From an engineering point-of-view, we performed experiments at increasing sample 


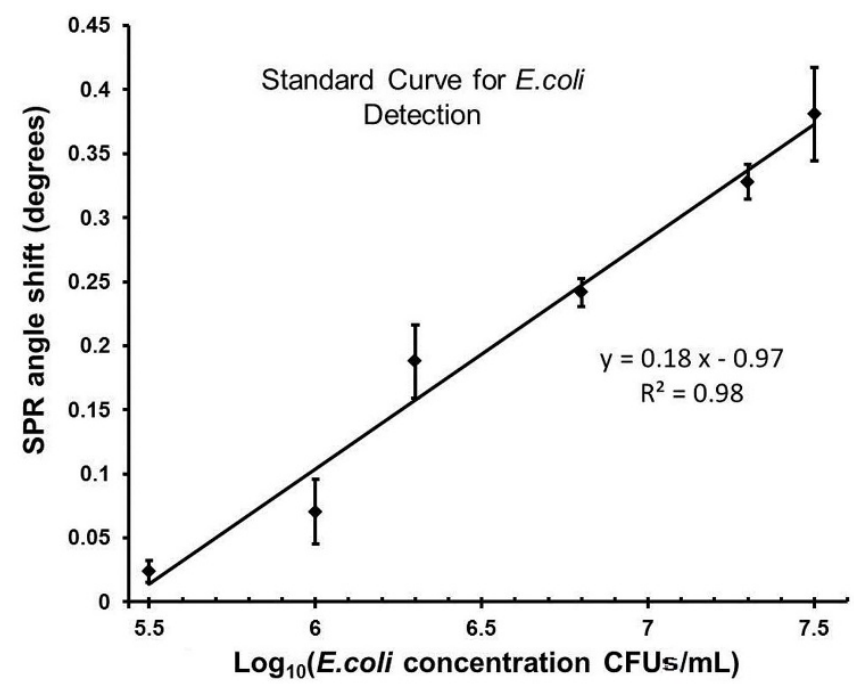

Figure $5 \mid$ Validation with $\boldsymbol{E}$. coli in PBS. The concentrations of $3.2 \times$ $10^{5} \mathrm{CFUs} / \mathrm{mL}, 10^{6} \mathrm{CFUs} / \mathrm{mL}, 2 \times 10^{6} \mathrm{CFUs} / \mathrm{mL}, 6.3 \times 10^{6} \mathrm{CFUs} / \mathrm{mL}, 2 \times$ $10^{7} \mathrm{CFUs} / \mathrm{mL}$, and $3.2 \times 10^{7} \mathrm{CFUs} / \mathrm{mL}$ were evaluated. At each concentration, 6 microchips were evaluated at $5 \mu \mathrm{L} /$ minute for 20 minutes. The linear curve shows the least squares fit with $\mathrm{R}^{2}=0.98(\mathrm{n}=$ 6 , error bars represent standard error of the mean).

volumes to evaluate detection limitations. Specifically, $10^{6} \mathrm{CFUs} / \mathrm{mL}$ of $E$. coli in $20 \mu \mathrm{L}$ PBS solution were applied to five chips for $4 \mathrm{~min}-$ utes, and the sensor recorded a $\sim 0.002^{\circ}$ shift in the resonance angle when chips were run at $5 \mu \mathrm{L} / \mathrm{min}$ (Figure $4 \mathrm{~d}$ ). The $\sim 0.002^{\circ}$ shift was found to result from $32 \pm 1.6 \mathrm{CFUs} / \mathrm{mL}$ of $E$. $\operatorname{coli}(\mathrm{n}=5$, and error is given in standard error of the mean). The instrument resolution $\left(\sim 0.002^{\circ}\right)$ reported in the calibration section is commensurate with the experimentally measured limitation $\left(\sim 0.002^{\circ}\right)$ at $20 \mu \mathrm{L}$ (see Calibration section under Materials and Methods). Further, $10^{6} \mathrm{CFUs} / \mathrm{mL}$ of E. coli spiked in $30 \mu \mathrm{L}$ PBS solution were applied to three other chips for 6 minutes, and a $0.004^{\circ}$ shift response was observed. Nine images at $10 \times$ magnification were used to count the bacteria, and it was found that the $\sim 0.004^{\circ}$ plasmon shift was

\section{Standard Curve For E. coli Detection} in PD Fluid

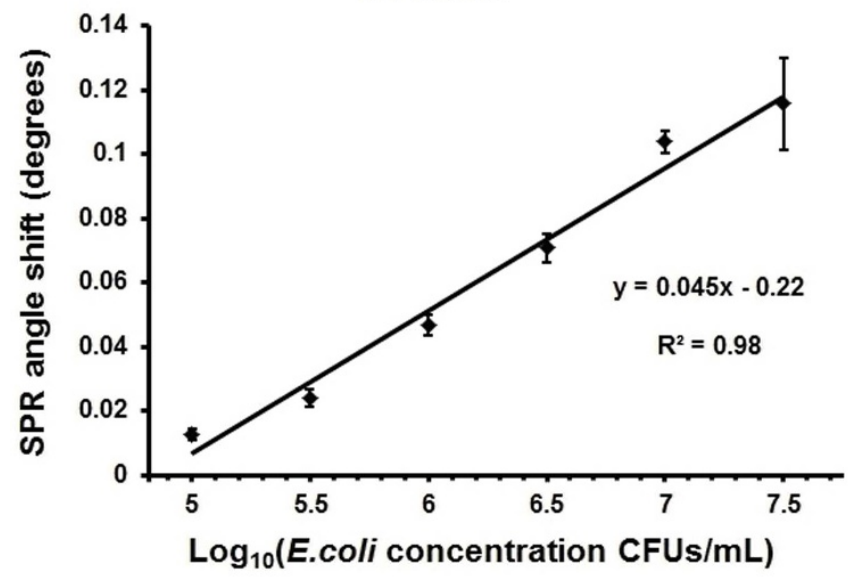

Figure 6 | Validation with $E$. coli spiked in peritoneal dialysis (PD) fluid. The concentration range of $10^{5} \mathrm{CFUs} / \mathrm{mL}$ to $3.2 \times 10^{7} \mathrm{CFUs} / \mathrm{mL}$ was evaluated. At each concentration, 6 microchips were evaluated at $5 \mu \mathrm{L} /$ minute for 20 minutes. The linear curve shows the least squares fit with $\mathrm{R}^{2}$ $=0.98(\mathrm{n}=6$, error bars represent standard error of the mean $)$. induced by $55 \pm 2.1$ CFUs/mL of $E$. coli captured within the active area (Figure S3). Here, a higher number of chips were run at increasing volumes, and the system responses were evaluated. We carefully characterized the platform and chose the most robust and reliable operating conditions. By considering platform performance and clinical applicability, $100 \mu \mathrm{L}$ sample volume was used in our experiments with $E$. coli. Since the measured signal levels in Figures 4, 5 and 6 were on the order of $0.1^{\circ}-0.3^{\circ}$ for $E$. coli, and are two orders of magnitude higher than the experimental instrument resolution $\left(\sim 0.002^{\circ}\right)$, the chosen volume of $100 \mu \mathrm{L}$ regularly provided reliable and robust conditions. The LOD can potentially be improved by incorporating on-chip or off-chip microfluidic functional elements to increase the capture efficiency. A good example of this would be utilizing the same fluid volume multiple times to increase the captured bacteria.

Specificity and Multiplexing. The specificity and selectivity of the proposed platform was evaluated with three sets of experiments. The first experiment was conducted by eluting E. coli over anti-LTA antibody-modified microfluidic chips. We observed that E. coli binding is minimum since anti-LTA antibody is specific for Gram + bacteria, which exhibited no affinity to E. coli (Figure 7a). As a result, there was minimal cross-reactivity (nonspecific binding) observed against $E$. coli on anti-LTA antibody-modified surfaces $\left(\Delta \theta=0.01^{\circ}\right)$ (Figure $\left.7 \mathrm{a}\right)$. The second experiment was designed by elution of $S$. aureus over anti-LTA modified surface. Figure $7 \mathrm{~b}$ shows the typical binding curve of $S$. aureus on anti-LTA-modified surface, which yielded $0.057^{\circ}$ shift in SPR angle. Further, as a third experiment (negative control), we examined a mixture of $S$. aureus and E. coli on anti-LTA antibody-modified surfaces (Figure 7c). Statistical analysis demonstrated that there is no significant difference between the results obtained from $S$. aureus and mixture cases $(\mathrm{n}=3, \mathrm{p}>0.05)$ (Figure 7d). Since E. coli has no significant interactions to the antiLTA antibody-modified surface (Figure 7a), the SPR angle shift originated due to $S$. aureus binding to the surfaces, confirming selective capture of $S$. aureus from the mixture. Additionally, the SPR angle change in E. coli experiments on the anti-LTA antibodymodified surfaces were observed to be statistically different than $S$. aureus and mixture experiments $(\mathrm{n}=3, \mathrm{p}<0.05)$. Thus, we demonstrated the specificity, selectivity and multiplexing capability of our platform.

The development of POC platforms is crucial both for field-based diagnostics and personalized medicine applications ${ }^{53,54}$. However, requirements for the portability of POC instruments hinder the transition of these devices to diagnostic and monitoring applications at the bed-side, primary care and resource-constrained settings. The presented platform incorporates a hand-held optical reader, which utilizes disposable microchips adaptable to portable and versatile POC applications. The system operates with small sample volumes $(100 \mu \mathrm{L})$, gives results within 20 minutes, and was made from inexpensive equipment. The portability of the device $(0.85 \mathrm{~kg})$ allows simple transportation without compromising sensitivity. The microchips can be disposed of without raising any contamination issues. The chip fabrication and surface activation procedures are high throughput, and the whole process can be automated in the future. Further, plasmonic-based technologies are label-free and detect the target directly with less complicated protocols compared to fluorescent techniques ${ }^{55}$. Plasmonics allow detection of ultralow concentrations of bioagents ${ }^{24,56,57}$. Therefore, merging microfluidics with plasmonic based technologies is enabling new operating modalities. For instance, recent developments in SPR imaging (SPRi) allowed high throughput on-chip sensors ${ }^{58}$ and on-chip immunoassays ${ }^{59}$. LSPR based platforms are also merging with microfluidics ${ }^{60}$. Development of such novel plasmonic-based microfluidic sensors will potentially contribute to infectious disease diagnosis and monitoring both at the POC and primary care settings. 
a
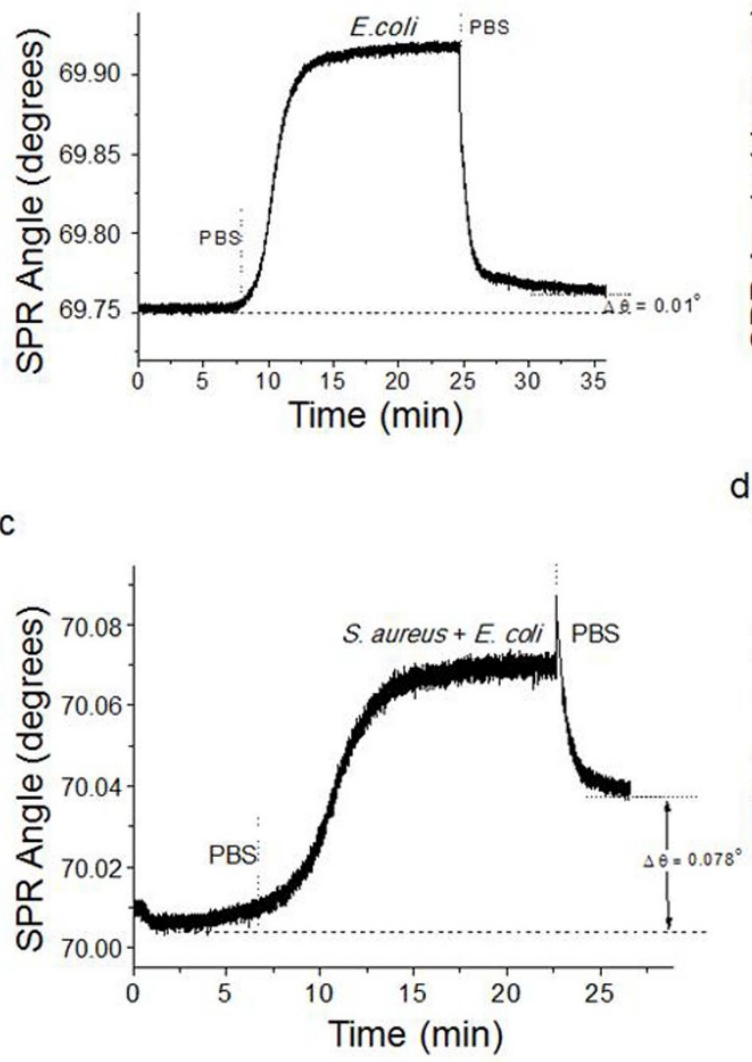

b

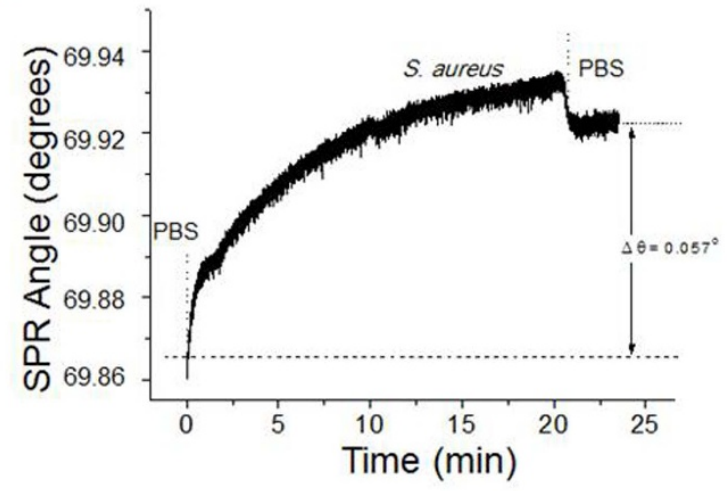

d

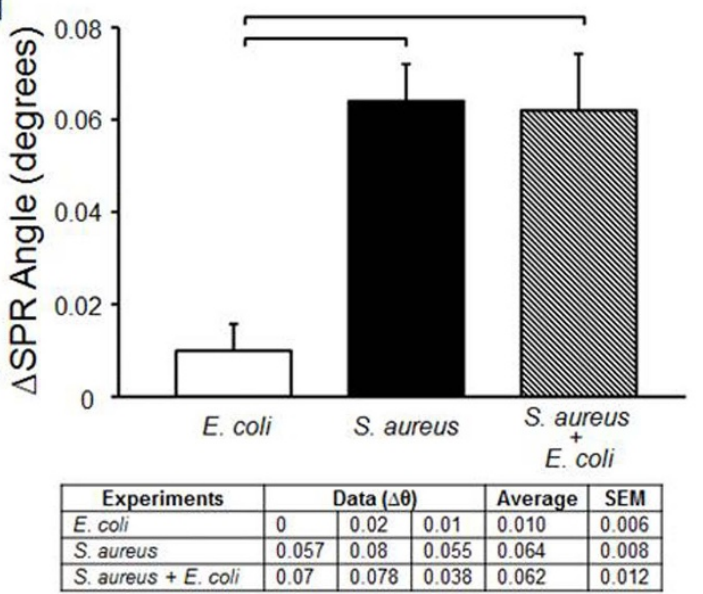

Figure 7 Specificity, selectivity and multiplexing of the SPR platform. SPR chips were decorated with anti-LTA antibodies, which are only specific to $S$. aureus (Gram + bacteria). (a) E. coli spiked in PBS $\left(5 \times 10^{6} \mathrm{CFUs} / \mathrm{mL}\right)$ were applied onto anti-LTA antibody modified surfaces. (b) S. aureus spiked in PBS $\left(5 \times 10^{6} \mathrm{CFUs} / \mathrm{mL}\right)$ were applied onto anti-LTA antibody modified surfaces. (c) For specificity and selectivity experiments, S. aureus and E. coli were mixed in PBS at the concentrations reported above. The mixture was then applied onto anti-LTA antibody modified surfaces. (d) Changes in SPR angle were recorded for each case. For statistical analysis, one-way analysis of variance (ANOVA) with Tukey's posthoc test was performed with Bonferroni's Multiple Comparison Test for equal variances for multiple comparisons. Statistical significance threshold was set at 0.05 ( $\mathrm{n}=3$, $\mathrm{p}<0.05$ ), and brackets represented statistical significant differences between groups. Error bars represented mean \pm standard errors of the mean (SEM).

\section{Conclusions}

We have developed a portable, label-free pathogen detection platform that merged microfluidic and SPR technologies on a single platform and demonstrated detection and quantification of bacterial pathogens. Using a plasmonic-based microchip sensitive pathogen detection is attained, which can potentially be used for POC applications. We further evaluated the response of the platform with detection of E. coli-spiked in PBS and PD fluid. The demonstrated system can potentially be generalized to other pathogens or for immunodiagnostics, given that there are well-defined biomarkers for the targeted applications. For instance, the presented platform is potentially applicable to other bacterial and viral diseases such as influenza, hepatitis, AIDS, and tuberculosis. Therefore, with the use of disposable, easy-to-fabricate and sensitive plasmonic surfaces with a specific surface chemistry on a label-free microfluidic platform, we address some of the major problems of current biosensing tools at the POC (i.e., portability, cost, small sample size and practical operation requirements).

1. Lee, W. G., Kim, Y. G., Chung, B. G., Demirci, U. \& Khademhosseini, A. Nano/ Microfluidics for diagnosis of infectious diseases in developing countries. Adv. Drug Deliv. Rev. 62, 449-457; DOI:10.1016/j.addr.2009.11.016 (2010).

2. Wang, S. Q., Inci, F., De Libero, G., Singhal, A. \& Demirci, U. Point-of-care assays for tuberculosis: Role of nanotechnology/microfluidics. Biotechnol. Adv. 31, 438-449; DOI:10.1016/j.biotechadv.2013.01.006 (2013).
3. Mani, V. et al. Emerging technologies for monitoring drug-resistant tuberculosis at the point-of-care. Adv. Drug Deliv. Rev. 78, 105-117; DOI:10.1016/ j.addr.2014.05.015 (2014).

4. Lissandrello, C. et al. Nanomechanical motion of Escherichia coli adhered to a surface. Appl. Phys. Lett. 105, 113701-1-113701-5; DOI:10.1063/1.4895132 (2014).

5. Sanderson, M. W., Sreerama, S. \& Nagaraja, T. G. Sensitivity of direct plating for detection of high levels of E-Coli O157: H7 in bovine fecal samples. Curr. Microbiol. 55, 158-161; DOI:10.1007/s00284-007-0083-4 (2007).

6. Wang, S. et al. Portable microfluidic chip for detection of Escherichia coli in produce and blood. Int. J. Nanomedicine 7, 2591-2600; DOI:10.2147/IJN.S29629 (2012).

7. Durmus, N. et al. Fructose-enhanced reduction of bacterial growth on nanorough surfaces. Int. J. Nanomedicine 7, 537-545; DOI:10.2147/IJN.S27957 (2012).

8. Jordan, J. A. \& Durso, M. B. Real-time polymerase chain reaction for detecting bacterial DNA directly from blood of neonates being evaluated for sepsis. J. Mol. Diagn. 7, 575-581; DOI:10.1016/S1525-1578(10)60590-9 (2005).

9. Chin, C. D., Linder, V. \& Sia, S. K. Lab-on-a-chip devices for global health: Past studies and future opportunities. Lab. Chip 7, 41-57; DOI:10.1039/b611455e (2007).

10. Yager, P. et al. Microfluidic diagnostic technologies for global public health. Nature 442, 412-418; DOI:10.1038/nature05064 (2006).

11. Tasoglu, S., Gurkan, U. A., Wang, S. \& Demirci, U. Manipulating biological agents and cells in micro-scale volumes for applications in medicine. Chem. Soc. Rev. 42, 5788-5808; DOI:10.1039/c3cs60042d (2013).

12. Cheng, X. H. et al. A microchip approach for practical label-free CD4+ T-cell counting of HIV-infected subjects in resource-poor settings. Jaids. 45, 257-261; DOI:10.1097/QAI.0b013e3180500303 (2007).

13. Yi, C., Li, C.-W., Ji, S. \& Yang, M. Microfluidics technology for manipulation and analysis of biological cells. Anal. Chim. Acta. 560, 1-23; DOI:10.1016/ j.aca.2005.12.037 (2006). 
14. Song, Y. S. et al. Microfluidics for cryopreservation. Lab. Chip 9, 1874-1881; DOI:10.1039/b823062e (2009).

15. Rizvi, I. et al. Flow induces epithelial-mesenchymal transition, cellular heterogeneity and biomarker modulation in 3D ovarian cancer nodules. Proc. Natl. Acad. Sci. USA 110, E1974-E1983; DOI:10.1073/pnas.1216989110 (2013).

16. Meyvantsson, I. \& Beebe, D. J. Cell Culture Models in Microfluidic Systems. Annu. Rev. Anal. Chem. 1, 423-449; DOI:10.1146/annurev.anchem.1.031207.113042 (2008).

17. White, A. K. et al. High-throughput microfluidic single-cell RT-qPCR. Proc. Natl. Acad. Sci. USA 108, 13999-14004; DOI:10.1073/pnas.1019446108 (2011).

18. Wang, S. Q. et al. Efficient on-chip isolation of HIV subtypes. Lab. Chip 12, 1508-1515; DOI:10.1039/c2lc20706k (2012).

19. Mark, D., Haeberle, S., Roth, G., von Stetten, F. \& Zengerle, R. Microfluidic lab-ona-chip platforms: requirements, characteristics and applications. Chem. Soc. Rev. 39, 1153-1182; DOI:10.1039/b820557b (2010).

20. Kim, Y. G., Moon, S., Kuritzkes, D. R. \& Demirci, U. Quantum dot-based HIV capture and imaging in a microfluidic channel. Biosens. Bioelectron. 25, 253-258; DOI:10.1016/j.bios.2009.06.023 (2009).

21. Shafiee, H. et al. Acute On-Chip HIV Detection Through Label-Free Electrical Sensing of Viral Nano-Lysate. Small 9, 2553-63; DOI:10.1002/smll.201202195 (2013).

22. Gurkan, U. A. et al. Miniaturized lensless imaging systems for cell and microorganism visualization in point-of-care testing. Biotechnol. J. 6, 138-149; DOI:10.1002/biot.201000427 (2011).

23. Myers, F. B. \& Lee, L. P. Innovations in optical microfluidic technologies for pointof-care diagnostics. Lab. Chip 8, 2015-2031; DOI:10.1039/b812343h (2008).

24. Inci, F. et al. Nanoplasmonic Quantitative Detection of Intact Viruses from Unprocessed Whole Blood. ACS Nano 7, 4733-4745; DOI:10.1021/nn3036232 (2013).

25. Kim, J. Joining plasmonics with microfluidics: from convenience to inevitability. Lab. Chip 12, 3611-3623; DOI:10.1039/c2lc40498b (2012).

26. Yanik, A. A. et al. An Optofluidic Nanoplasmonic Biosensor for Direct Detection of Live Viruses from Biological Media. Nano Lett. 10, 4962-4969; DOI:10.1021/ nl103025u (2010).

27. Sevimli, S., Inci, F., Zareie, H. M. \& Bulmus, V. Well-Defined Cholesterol Polymers with pH-Controlled Membrane Switching Activity. Biomacromol. 13, 3064-3075; DOI:10.1021/bm300846e (2012).

28. Shafiee, H. et al. Nanostructured Optical Photonic Crystal Biosensor for HIV Viral Load Measurement. Sci. Rep. 4, 4116; DOI:10.1038/srep04116 (2014).

29. Brolo, A. G. Plasmonics for future biosensors. Nat. Photonics 6, 709-713; DOI:10.1038/nphoton.2012.266 (2012).

30. Piliarik, M. \& Homola, J. Surface plasmon resonance (SPR) sensors: approaching their limits? Opt. Express. 17, 16505-16517; DOI:10.1364/OE.17.016505 (2009).

31. Arlett, J. L., Myers, E. B. \& Roukes, M. L. Comparative advantages of mechanical biosensors. Nat. Nanotechnol. 6, 203-215; DOI:10.1038/nnano.2011.44 (2011).

32. Wang, S. Q. et al. Simple filter microchip for rapid separation of plasma and viruses from whole blood. Int. J. Nanomedicine 7, 5019-5028; DOI:10.2147/ ijn.s32579 (2012).

33. Kretschmann, E. \& Raether, H. Radiative decay of non radiative surface plasmons excited by light. Z. Naturforsch. 23a, 2135-2136 (1968).

34. Turker, B. et al. Grating coupler integrated photodiodes for plasmon resonance based sensing. Lab. Chip 11, 282-287; DOI:10.1039/c0lc00081g (2011).

35. Homola, J. Springer Series on Chemical Sensors and Biosensors, Homola, J. (ed.), Vol. 4 (Springer Berlin Heidelberg, 2006).

36. Moon, S. et al. Integrating microfluidics and lensless imaging for point-of-care testing. Biosens. Bioelectron. 24, 3208-3214; DOI:10.1016/j.bios.2009.03.037 (2009).

37. Homola, J., Yee, S. S. \& Gauglitz, G. Surface plasmon resonance sensors: review. Sensors Actuat. B-Chem. 54, 3-15; DOI:10.1016/s0925-4005(98)00321-9 (1999).

38. Homola, J. Surface Plasmon Resonance Sensors for Detection of Chemical and Biological Species. Chem. Rev. 108, 462-493; DOI:10.1021/cr068107d (2008).

39. Puttharugsa, C. et al. Development of surface plasmon resonance imaging for detection of Acidovorax avenae subsp citrulli (Aac) using specific monoclonal antibody. Biosens. Bioelectron. 26, 2341-2346; DOI:10.1016/j.bios.2010.10.007 (2011)

40. Abdulhalim, I., Zourob, M. \& Lakhtakia, A. Surface Plasmon Resonance for Biosensing: A Mini-Review. Electromagnetics 28, 214-242; DOI:10.1080/ 02726340801921650 (2008).

41. Tawil, N., Sacher, E., Mandeville, R. \& Meunier, M. Surface plasmon resonance detection of E. coli and methicillin-resistant S. aureus using bacteriophages. Biosens. Bioelectron. 37, 24-29; DOI:10.1016/j.bios.2012.04.048 (2012).

42. Barlen, B., Mazumdar, S. D., Lezrich, O., Kampfer, P. \& Keusgen, M. Detection of salmonella by surface plasmon resonance. Sensors 7, 1427-1446; DOI:10.3390/ s7081427 (2007)

43. Taylor, A. D., Yu, Q., Chen, S., Homola, J. \& Jiang, S. Comparison of E. coli O157 : H7 preparation methods used for detection with surface plasmon resonance sensor. Sensors. Actuat. B-Chem. 107, 202-208; DOI:10.1016/ j.snb.2004.11.097 (2005)

44. Tokel, O., Inci, F. \& Demirci, U. Advances in Plasmonic Technologies for Point of Care Applications. Chem. Rev. 114, 5728-5752; DOI:10.1021/cr4000623 (2014).

45. Waswa, J., Irudayaraj, J. \& DebRoy, C. Direct detection of E. Coli O157 : H7 in selected food systems by a surface plasmon resonance biosensor. LWT - Food Sci. Technol. 40, 187-192; DOI:10.1016/j.lwt.2005.11.001 (2007).
46. Subramanian, A., Irudayaraj, J. \& Ryan, T. A mixed self-assembled monolayerbased surface plasmon immunosensor for detection of E. coli O157 : H7. Biosens. Bioelectron. 21, 998-1006; DOI:10.1016/j.bios.2005.03.007 (2006).

47. Waswa, J. W., Debroy, C. \& Irudayaraj, J. Rapid detection of Salmonella Enterritidis and Escherichia Coli using surface plasmon resonance biosensor. J. Food Process. Eng. 29, 373-385; DOI:10.1111/j.1745-4530.2006.00071.x (2006).

48. Dudak, F. C. \& Boyacı, İ. H. Development of an immunosensor based on surface plasmon resonance for enumeration of Escherichia coli in water samples. Food Res. Int. 40, 803-807; DOI:10.1016/j.foodres.2007.01.011 (2007).

49. Taylor, A. D. et al. Quantitative and simultaneous detection of four foodborne bacterial pathogens with a multi-channel SPR sensor. Biosens. Bioelectron. 22, 752-758; DOI:10.1016/j.bios.2006.03.012 (2006).

50. Oh, B. K., Kim, Y. K., Bae, Y. M., Lee, W. H. \& Choi, J. W. Detection of Escherichia coli O157:H7 using immunosensor based on surface plasmon resonance. J. Microbiol. Biotechn. 12, 780-786 (2002).

51. Maalouf, R. et al. Label-Free Detection of Bacteria by Electrochemical Impedance Spectroscopy: Comparison to Surface Plasmon Resonance. Anal. Chem. 79, 4879-4886; DOI:10.1021/ac070085n (2007).

52. Biacore 3000 GoldSeal. http://www.gelifesciences.com/webapp/wcs/stores/servlet/ productById/en/GELifeSciences/28961825, (Accessed, 11th November 2014).

53. Laursen, L. Point-of-care tests poised to alter course of HIV treatment. Nat. Med. 18, 1156-1156; DOI:10.1038/nm0812-1156 (2012).

54. Gallegos, D. et al. Label-free biodetection using a smartphone. Lab. Chip 13, 2124-2132; DOI:10.1039/c3lc40991k (2013).

55. Mayer, K. M. \& Hafner, J. H. Localized Surface Plasmon Resonance Sensors. Chem. Rev. 111, 3828-3857; DOI:10.1021/cr100313v (2011).

56. Brolo, A. G. Plasmonics for future biosensors. Nat. Photonics 6, 709-713; DOI:10.1038/nphoton.2012.266 (2012).

57. Anker, J. N. et al. Biosensing with plasmonic nanosensors. Nat. Mater. 7, 442-453; DOI:10.1038/nmat2162 (2008).

58. Lee, K.-H., Su, Y.-D., Chen, S.-J., Tseng, F.-G. \& Lee, G.-B. Microfluidic systems integrated with two-dimensional surface plasmon resonance phase imaging systems for microarray immunoassay. Biosens. Bioelectron. 23, 466-472; DOI:10.1016/j.bios.2007.05.007 (2007)

59. Luo, Y., Yu, F. \& Zare, R. N. Microfluidic device for immunoassays based on surface plasmon resonance imaging. Lab. Chip 8, 694-700; DOI:10.1039/ b800606g (2008).

60. Huang, C. et al. Localized surface plasmon resonance biosensor integrated with microfluidic chip. Biomed. Microdevices 11, 893-901; DOI:10.1007/s10544-0099306-8 (2009).

\section{Acknowledgments}

This work was supported by the National Institute of Health under NIH award numbers R01AI093282, R01AI081534, R21AI087107, and NIH U54EB15408, NIH F32AI102590. We thank Brigham and Women's Hospital (BWH) Biomedical Research Institute Translatable Technologies \& Care Innovation Award. We also thank Albert Wang and Nick Petrusev for helpful discussions. The gold coated chips were fabricated using facilities at the Center for Nanoscale Systems (CNS), a member of the National Nanotechnology Infrastructure Network (NNIN).

\section{Author contributions}

O.T., A.D. and U.D. developed the idea; A.D. and U.D. collaborated on the paper; O.T., A.D. and U.D. designed the experimental approach; O.T., U.H.Y., F.I., N.G.D., O.O.E., B.T., C.C., S.R., K.S., N.N. and H.S. performed the experiments; O.T., U.H.Y., F.I. and U.D. analyzed the data; O.T., U.H.Y., F.I., A.D. and U.D. wrote the manuscript. All authors reviewed the manuscript.

\section{Additional information}

Supplementary information accompanies this paper at http://www.nature.com/ scientificreports

Competing financial interests: Yes, there is a potential competing financial interest. Dr. U. Demirci is a founder of, and has an equity interest in: (i) DxNow Inc., a company that is developing microfluidic and imaging technologies for point-of-care diagnostic solutions, and (ii) Koek Biotech, a company that is developing microfluidic IVF technologies for clinical solutions. Dr. U. Demirci's interests were viewed and managed by the Brigham and Women's Hospital and Partners HealthCare in accordance with their conflict-of-interest policies.

How to cite this article: Tokel, O. et al. Portable Microfluidic Integrated Plasmonic Platform for Pathogen Detection. Sci. Rep. 5, 9152; DOI:10.1038/srep09152 (2015).

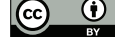

This work is licensed under a Creative Commons Attribution 4.0 International License. The images or other third party material in this article are included in the article's Creative Commons license, unless indicated otherwise in the credit line; if the material is not included under the Creative Commons license, users will need to obtain permission from the license holder in order to reproduce the material. To view a copy of this license, visit http://creativecommons.org/licenses/by/4.0/ 